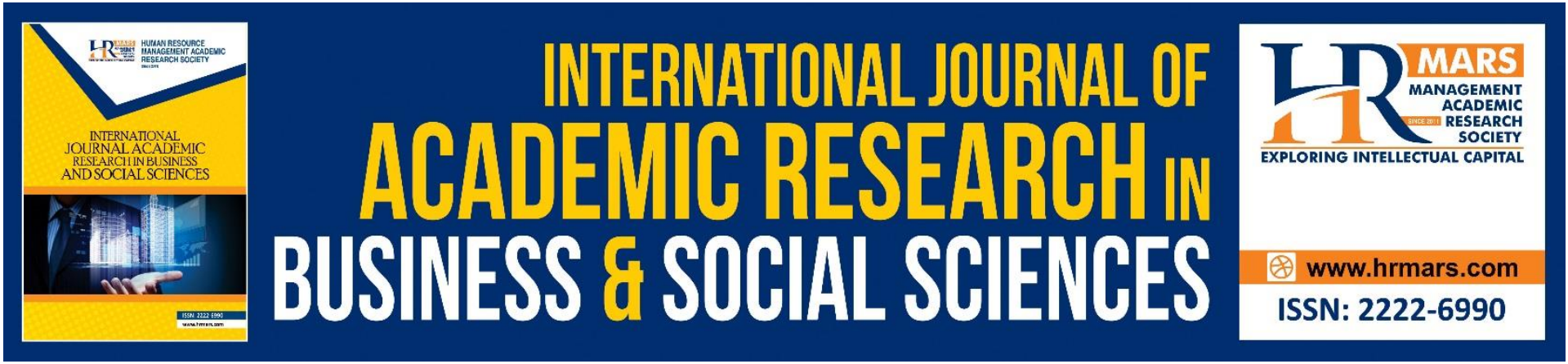

\title{
The Effects of Augmentative and Alternative Communication Intervention on Social Communication Skills for Children with Learning Disabilities
}

\author{
Norfishah Mat Rabi, Nurul Shahida Nordin
}

To Link this Article: http://dx.doi.org/10.6007/IJARBSS/v11-i1/9004

DOI:10.6007/IJARBSS/v11-i1/9004

Received: 11 December 2020, Revised: 13 January 2021, Accepted: 23 January 2021

Published Online: 31 January 2021

In-Text Citation: (Rabi \& Nordin, 2021)

To Cite this Article: Rabi, N. M., \& Nordin, N. S. (2021). The Effects of Augmentative and Alternative Communication Intervention on Social Communication Skills for Children with Learning Disabilities. International Journal of Academic Research in Business and Social Sciences, 11(1), 833-842.

Copyright: @ 2021 The Author(s)

Published by Human Resource Management Academic Research Society (www.hrmars.com) This article is published under the Creative Commons Attribution (CC BY 4.0) license. Anyone may reproduce, distribute, translate and create derivative works of this article (for both commercial and non-commercial purposes), subject to full attribution to the original publication and authors. The full terms of this license may be seen at: http://creativecommons.org/licences/by/4.0/legalcode

Vol. 11, No. 1, 2021, Pg. 833 - 842

Full Terms \& Conditions of access and use can be found at http://hrmars.com/index.php/pages/detail/publication-ethics 


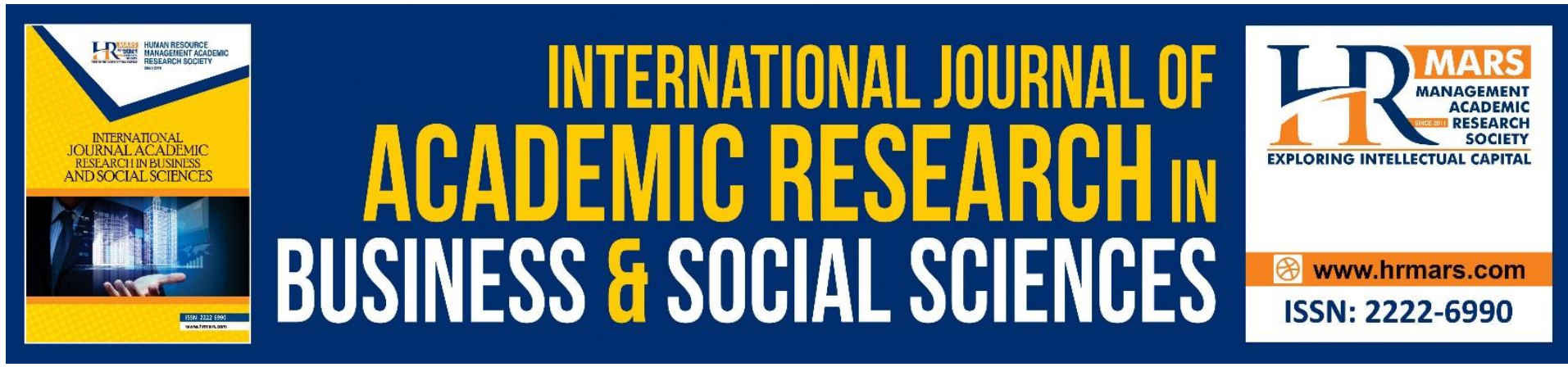

\title{
The Effects of Augmentative and Alternative Communication Intervention on Social Communication Skills for Children with Learning Disabilities
}

\author{
Norfishah Mat Rabi, Nurul Shahida Nordin \\ Faculty of Human Development, Universiti Pendidikan Sultan Idris, Malaysia
}

\begin{abstract}
Most children with learning disabilities faced problem in social communication skill and its really affects their life and learning process in school. To enhance social communication skill, an effective intervention should be applied to them. This case study was conducted to confirm that AAC (augmentative and alternative communication) is an effective way in enhancing social communication skill among children with learning disabilities. The objective of this study were to identify the impact of using $A A C$ in verbal and nonverbal communication and skill in social interaction. Respondents consisted of 30 children with learning disabilities, aged eight to twelve years, from three primary school in Perak. Observation were done in teaching and learning process in the classroom which took about 40 minutes for each session. Data collection were conducting through observations. Research finding proven that AAC were strongly assisted children with learning disabilities to communicate and socially interact. Results shows that participants had improved $22.07 \%$ in verbal communication, $21.76 \%$ in nonverbal communication and $0.16 \%$ in social communication skill. Implication of the study shows that $A A C$ is applicable in enhancing verbal and nonverbal communication but not in social interaction. However, AAC can be used as an alternative method to improve social communication skill of children with learning disabilities. Significant of the study is to give new perspective to everyone who is engaging life with learning disabilities children to be creative in teaching social communication skill for them.
\end{abstract}

Keyword: Augmentative and Alternative Communication (AAC), Children with Learning Disabilities, Intervention, Social Communication

\section{Introduction}

Communication skill is a two-way process in which participants exchange information, ideas, feelings, and opinions. It is vitally important, as it is one of the most basic elements of human functioning, and is the cornerstone of strong, healthy interpersonal relationships (Erozkan, 2013). When people experience difficulties to express verbally what they intend to communicate, interaction problems arise, leading to emotional, social, and cognitive problems. If verbal communication does not occur naturally because of constraints in people's and environments capabilities, it is necessary to design alternative means (Ascari, 
Pereira \& Silva, 2018). While speech is always the most natural way to communicate, there are definitely other excellent possibilities, and it is essential that a student has some means of consistent control over his/her environment. Communication should extend beyond conveying basic wants and needs and individuals should be able to independently express all aspects of their personality. When language and communication improved, nonspeaking children with disabilities could be accessed to curriculum, social interaction, and manage behavior.

Lack of language knowledge has certainly influenced communication and social interaction in children with learning disabilities. As example, children with intellectual disabilities or autism characteristically have limited skills to interact effectively with teachers and peers. DeBortoli, Arthur-Kelly, Mathisen, and Balandin (2014) stated that children with moderate to severe disabilities often show delays in their language acquisition and they have difficulty engaging in communicative interactions. Problems in social interaction and communication become a barrier for children with learning disabilities to have friends and to live in the community. Social skills are a collection of learned behaviors giving the individual the ability to have an influential relationship with others and to abstain from socially unreasonable reactions (Agran, Hughes, Thoma, \& Scott, 2016; Davies, Cooper, Kettler \& Elliott, 2015; Gresham, 2016). Social skills are a collection of learned behaviors giving the individual the ability to have an influential relationship with others and to abstain from socially unreasonable reactions.

\section{Literature Review}

Use of suitable and clear teaching media can give positive impact to social communication skill. As example, multimedia computer-assisted instruction were effective for improving and maintaining student alphabet recognition skills (Travers et al., 2011). This is because the multimedia computer-assisted instruction make used of sensory stimulus through verbal, visual and auditory. Alternative and augmentative communication is a type of intervention that uses manual signs, communication boards with symbols, devices that produce synthesized voice, all these whilst trying to incorporate all communication skills of the child (Simion, 2014). Communication skill is a two-way process in which participants exchange information, ideas, feelings, and opinions. It is vitally important, as it is one of the most basic elements of human functioning, and is the cornerstone of strong, healthy interpersonal relationships (Erozkan, 2013). To acquire skill ini social communication, student must be exposed to systematic learning or training program such as verbal and non-verbal communication, speech ability and social skills (Rabi et al., 2020).

Early Augmentative and Alternative Communication (AAC) interventions in school environments aim to support the development of the communication skills of children with complex communication needs (Radici, Heboyan, Mantovani \& Leo (2019). Augmentative and Alternative Communication (AAC) aims to complement or replace speech to compensate difficulties of expression by using non-verbal communication systems and intervention strategies (Simion, 2014). One of the goals of AAC intervention is to determine the communication, behavioral and social needs, identify strengths and match those strengths to possible solutions. The American Speech and Hearing Association (ASHA) refers that Augmentative and Alternative Communication (AAC) covers all forms of alternative communication in speech, being used to express thoughts, needs, requests and ideas of people with complex communicative needs (Cesa \& Mota, 2017). While communication may be challenging for some children with learning disabilities, they possess many strengths that 
lend them to being able to successfully use different types of communication strategies. AAC is a strategies that improve communication for those who are non-speaking and natural speech does not meet their needs for functional communication. Augmentative communication systems complement oral language when it is not possible to communicate effectively with other people and the environment (Ascari, Pereira \& Silva, 2018) by using non-verbal communication and intervention strategies. AAC provides non-speaking individuals the ways to greet others, ask questions, gain information, engage in social interaction, give comments, tell jokes, recall past experiences, tell stories, and show empathy or sympathy. With AAC support, people with communication problems can interact with other people, expressing opinions, feelings and make decisions for their lives.

\section{Methodology}

This study examines specifically on the effects of augmentative and alternative communication intervention on social communication skills for children with learning disabilities. This study uses purposive sampling. The sample of the study is 30 children with learning disabilities from three primary school were selected in this study. Participants were placed in the Integration Program for Learning Difficulties (IPLP) in government school. Participants were chosen based on the information given by the school teacher. From the IEP (Individual Educational Program) report, respondents has shown having problem in verbal communication, non-verbal communication and social interaction.

For data collection, this study uses quasi experimental research method. A quasiexperiment is an empirical interventional study used to estimate the causal impact of an intervention on target population without random assignment. With random assignment, study participants have the same chance of being assigned to the intervention group or the comparison group. As a result, differences between groups on both observed and unobserved characteristics would be due to chance, rather than to a systematic factor related to treatment. The study was conducted to assist children with learning disabilities to enhance social communication skill with the use of AAC. This study is designed for a duration of 10 weeks. The time taken for learning activities is 30 minutes for each session. For data collection, checklist had been used in the observation together with the video recording to record activities. The student was then evaluated on his/her ability to communicate verbal and non-verbal, and ability to interact with others in the learning session.

\section{Types of AAC for intervention}

AAC is used as intervention in learning activities, involving (1) No Technology (these are "unaided" systems an individual uses with no additional tools or technology such as motor behaviors, gestures, vocalizations, verbalizations (or verbal approximations), proxemics (approach or avoidance of a communication partner), eye gaze, and facial expressions. These AAC systems involve only the individual's body. Some systems involve formalized languages, such as American Sign Language (ASL). A form of alternative and augmentative communication in which someone physically supports an autistic person and helps him to point at pictures or words. (2) Low Technology involve the use of equipment that is not electronic. Low tech communication aids are often paper based and include communication books, charts etc. (3) Light Technology is a voice output communication systems which are typically battery operated and have a static (non-changing) display. (4) High Technology describes all electronic communication aids from single message switches to sophisticated, computer based communication systems that have many additional features. Mobile Devices 
is a range of portable devices such as mobile (cell) phones and tablets. Systems typically requiring an electronic power source and having a dynamic (changing - i.e., computerized LCD screen) display such as an iPad (with an appropriate AAC app). Electronic communication aids allow the user to use picture symbols, letters and complete phrases to create messages. Some devices can be programmed to speak more than one language. AAC provide tools such as visual schedules and calendars to help individuals with autism organize their lives and understand sequence and time.

\section{Results}

The findings showed that AAC can improve social communication skill among children with learning disabilities. Finding is reported based on verbal communication, non-verbal communication and social interaction. The researcher determined the participants' achievement using frequency and level of achievement. To compare the achievement among participants, researcher divided the level into three levels. Low level of achievement means, the changes is small, whereas for high level, the changes is big.

\section{Verbal Communication Skill}

AAC is proven to be the most effective tool to assist participants to communicate verbally. 10 skills is determined to be acquired by participants during the intervention using AAC. The 10 skills were GOS (Give opinion about something), AQ (Ask question), GIL (Give idea to show interest in lesson), ICT (Initiate conversation on topic learnt), MCT (Maintaining conversation on topic learnt), EUC (End up conversation in discussion), GCD (Give comment in discussion), PST (Predicts on something in topic learnt), GI (Give instruction), and AQS (Answer question spontaneously on topic learnt). The result is shown in Figure 1.

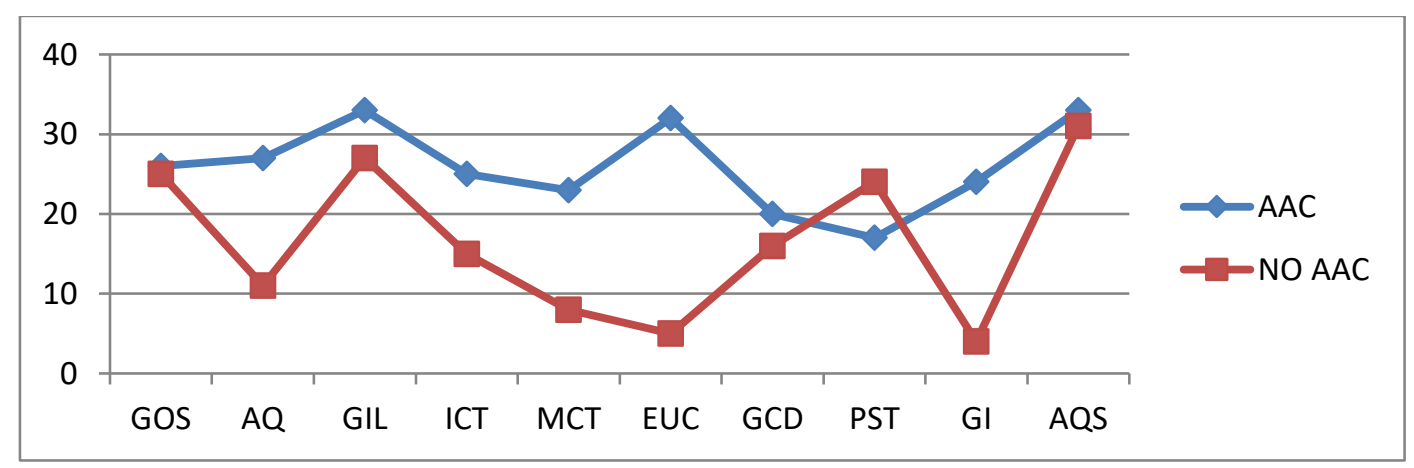

Fig. 1: Verbal communication skills

Figure 1 showed that participant had improved a lot in verbal communication skills when using AAC. Total score for verbal communication with AAC is $61.03 \%$ whereas results for without $A A C$ is $38.97 \% .10$ skills were listed in the intervention and has been observed during learning activities done. Findings shows that the most effective skill was achieved by respondent was an ability to 'end up conversation in discussion (EUC)' and 'give instruction (GI)'. Without AAC, the score in 'end up conversation in discussion (EUC)' was 5 but with AAC, the skill was improved to 32. For 'give idea to show interest in lesson (GIL)', Give opinion about something (GOS)' and 'answer question spontaneously on topic learnt (AQS)', result shows very little differences between with and without AAC. For skill in 'predicts on something in topic learnt (PST)', participants shows better achievement in without AAC than with AAC. According to level of achievement, there were four low level (GOS, GIL, GCD, AQS), three 
average level (AQ, ICT, MCT) and one high level (GI). Overall result shows that nine verbal communication skill were successfully improved by using AAC whereas only one skill did not show improvement. However, the use of AAC intervention is greatly recommended for teachers and parent to help children with disabilities improve verbal communication skills.

Non-verbal Communication

Skill in non-verbal communication shows an average improvement among participants through the intervention. With AAC, participants shows high score compare to without AAC. It is proven that, the use of AAC was effective in helping children with disabilities to improve non-verbal communication skill. 10 skills were identified to be enhanced with the use of AAC intervention. The 10 skills were SWF (Shows something with finger), NHU (Nodded head to show understanding on what teacher said), SHU (Shake head to show not understanding on what teacher say), RHS (Raise hand when to say something), UHF (Understanding happy face), USF (Understanding sad face), UAF (Understanding angry face), UDS (Understanding dislike on something), SBL (Use suitable body language), UGS (Use gesture to say something). Figure 2 shows the result of intervention using AAC in non-verbal communication.

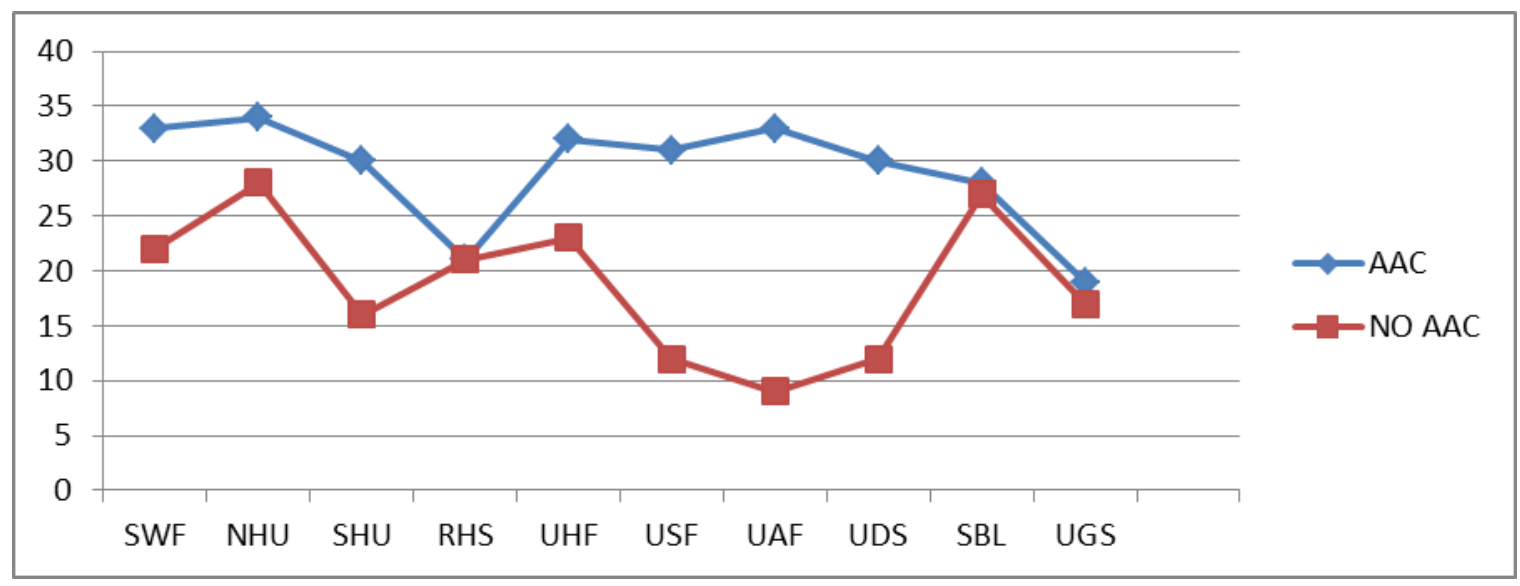

Fig. 2 Non-verbal Communication

Figure 2 showed that participants has improved a lot in nonverbal communication skills when using AAC With AAC, participants shows $60.88 \%$ score in non-verbal communication compared to without AAC with $39.12 \%$. The highest score is in 'understanding angry face (UAF)' which was improved from 9 to 33 score. It is very obvious that AAC helped participants to understand other people in angry mood. For the skill in 'raise hand when to say something (RHS)' and 'use suitable body language (SBL)', there is no difference between with AAC or without AAC. Overall result shows that three nonverbal skills were achieved high level (USF, UAF, UDS) and low level (RHS, SBL, UGS) of achievement whereas, two skills showed average level (SHU, UHF). However, result proven that nine skills in non-verbal communication are improved with the use of AAC.

\section{Social Interaction}

In social interaction, AAC intervention almost have no differences in helping children with disabilities to improve the skill. The 10 skills were LEF (Look into eyes and face when speak with someone), STO (Smile to others), CHF (Claps hand when friend answers correctly), LOS (Look to the other side when teacher speak), GAS (Give attention to others when speak), ARP (Accepted request to play together), DAT (Do activities together), MAF (Can mixed 
around with friend), RF (Recognize friend) and USS (Understand social situation (ie: laugh when friend). Figure 3 shows the result of using AAC in the social interaction skill.

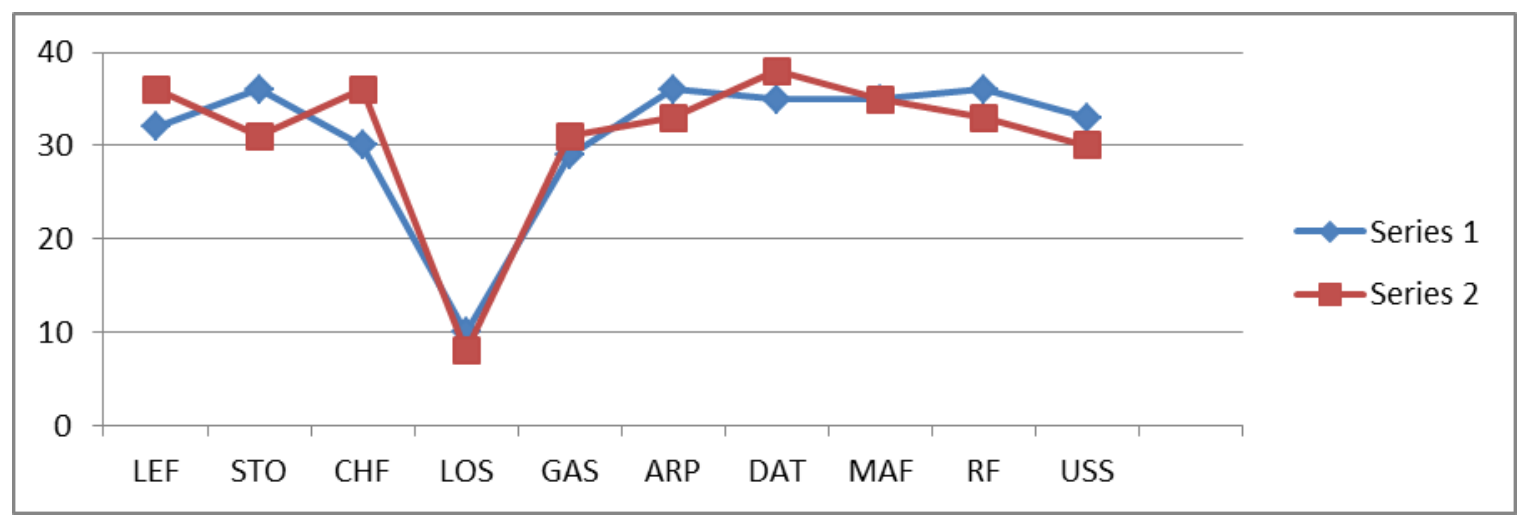

Fig. 3 Social Interaction

Figure 3 showed that participants not much improved in social interaction skills when using AAC. With AAC, participants shows $50.11 \%$ score compared to without AAC with $49.99 \%$. The highest score is in 'understanding angry face (UAF)' which was improved from 9 to 33 score. It is very obvious that AAC helped participants to understand other people in angry mood. For the skill in 'raise hand when to say something (RHS)' and 'use suitable body language (SBL)', there is no difference between with AAC or without AAC. However, result proven that nine skills in non-verbal communication are improved with the use of AAC. Result proven that participants have good social interaction whether with or without AAC. Some skill was better without AAC such as 'look into eyes and face when speak with someone, claps hand when friend answers correctly, give attention to others when speak, and do activities together'. The skill improved were 'smile to others, look to the other side when teacher speak, accepted request to play together, and understand social situation'. Overall result shows that three nonverbal skills were achieved high level (USF, UAF, UDS) and low level (RHS, SBL, UGS) of achievement whereas, two skills showed average level (SHU, UHF).

\section{Discussion}

Most children with learning disabilities have problems in social communication and as a result, they hardly communicate and interact socially with others. Obviously, it is difficult for them to mixed around with people. In order to foster and enhance social communication skill, multiple intervention should be given to them. For children with learning disabilities such as autism, using stimulus in teaching process is an effective way to help them communicate. Without targeted interventions on social communication skills, children with ASD are at risk for isolation from peers and may not obtain optimal benefits from early social communication opportunities (Ferraioli \& Harris, 2011). Many studies have shown positive effects for social communication interventions using packaged interventions composed of evidence-based antecedent and behavioral strategies (e.g., Koegel et al.2012). It is advisable for teachers to use suitable intervention and it should depend on the needs and type of problems faced.

Social communication skill is very important for children to be accepted among peers in school environment. In school settings, children with high rates of challenging behavior often have fewer opportunities for pro-social interactions with peers (Ferraioli \& Harris, 2011). In addition, limited or impaired play repertoires can restrict access to naturally embedded social communication opportunities in preschool (Kasari et al., 2013; Barton \& 
Pavilanis, 2012). To be able to communicate verbally, a child must have a skill in giving opinion, ask question, give idea to show interest in lesson, initiate conversation on topic learnt, maintaining and end up conversation on topic learn, give comment in discussion, predicts on something in topic learn, give instruction, and answer question spontaneously on topic learn. Findings is supported by previous studies which also focus on intervened on either initiating or maintaining a conversation (Laushey et al., 2009) examined an intervention to increase appropriate responding to questions from peers.

Beside verbal communication, social communication also involving nonverbal such as shows something with finger, nodded head to show understanding on what teacher said, shake head to show not understanding on what teacher say, raise hand when to say something, understanding happy, sad, and angry face, understanding dislike on something, use suitable body language, and use gesture to say something. The important of verbal communication also mentioned in previous studies on how interventions were implemented to address facial expression, both appropriate response (e.g., smiling) and appropriate reading official cues (Scattone, 2008; Laushey et al., 2009). Such skill such as conflict resolution, empathy, or joke telling, are critical social communication skills typically already learned by children in early years of school (Lillard et al., 2013).

For social interaction skills, it can be shown in ability to look into eyes and face when speak with someone, smile to others, claps hand when friend answers correctly, look to the other side when teacher speak, give attention to others when speak, accepted request to play together, do activities together, can mixed around with friend, recognize friend, and understand social situation (ie: laugh when friend make jokes). Restricted or preservative interests can impede positive social interactions with peers such as extended and reciprocal conversations and play (Leekham et al., 2011). In children who are typically developing, both humor and conversations become notably more sophisticated in the early elementary years (Neely et al., 2012).

This study proven that AAC helped children with learning disabilities to enhance social communication skill. Augmentative and Alternative Communication (AAC) aims to complement or replace speech to compensate difficulties of verbal expression. AAC systems can provide technological support for people with speech disorders, assisting in the inclusion, learning and sharing of experiences (Ascari, Pereira \& Silva, 2018). For children with learning disabilities, ability to communicate does not develop naturally due to chronological age but depends on developmental age. They must be disclosed in a social environment so that they can better understand how to get along with others. They must have experience in dealing with other people so they can build social interaction and communication with the public. Indeed, experience in the environment can also stimulate their ability to speak. Children with learning disabilities needs help in the acquisition of language by using various sources in the environment. They need a variety of resources to cultivate them to speak like using AAC. Children with learning disabilities can think in a visual way and recall visual images and memories easily. They can understand and benefit from concrete and visual information regarding daily events. None of the individuals involved in any of the studies demonstrated decreases in speech production as a result of AAC intervention. The majority demonstrated at least modest gains in speech (a small percentage showed no change). In reality, AAC can be used very effectively in conjunction with therapy, and may enable the student to immediately participate in communicative interactions with peers and others in school, at home, and in the community. 


\section{Conclusion}

The development in social communication skills is essential for children with learning disabilities to be placed in inclusive education program in Malaysia. The results of this study suggesting the need for additional effective interventions to help children improve social communication skill. Research and practice should explore an alternative intervention on advanced social communication skills, and instruction within a school context. In addition, the use of AAC does not minimize language development naturally. This is because AAC presented better understanding of language based on concept of things being learn.

\section{Acknowledgement}

The authors would like to express their highest gratitude to the Ministry of Higher Education Malaysia for the funding of this research project (Fundamental Research Grant Scheme /FRGS) via code number FRGS/1/2017/SSI09/UPSI/02/12.

\section{Corresponding Author}

Norfishah Mat Rabi

Faculty of Human Development, Universiti Pendidikan Sultan Idris, Malaysia

Email: norfishah@fpm.upsi.edu.my

\section{Reference}

Agran, M., Hughes, C., Thoma, C., \& Scott, L. (2016). Employment social skills: What skills are really valued? Career Development and Transition for Exceptional Individuals, 39, 111-120.

Ascari, R. E. O. S., Pereira, R., \& Silva, L. (2018). Mobile Interaction for Augmentative and Alternative Communication: a Systematic Mapping. SBC Journal on Interactive Systems, 9(2).

Barton, E. E., \& Pavilanis, R. (2012). Teaching pretend play to young children with autism. Young Exceptional Children, 15(1), 5-17.

Cesa, C. C., \& Mota, H. B. (2017). Augmentative and alternative communication: from qualification to speech, language and hearing science clinical practice. Rev. CEFAC, 19(4), 529-538.

Davies, M., Cooper, G., Kettler, R.J., \& Elliott, S. (2015). Developing Social Skills of Students with Additional Needs Within the Context of the Australian Curriculum. Australasian Journal of Special Education, 39(1), 37-55.

DeBortoli, T., Arthur-Kelly, M., Mathisen, B., \& Balandin, S. (2014). Speech-Language Pathologists' Perceptions of Implementing Communication Intervention with Students with Multiple and Severe Disabilities. Augmentative and Alternative Communication, 30(1), 55-70.

Erozkan, A. (2013). The Effect of Communication Skills and Interpersonal Problem Solving Skills on Social Self-Efficacy. Educational Sciences: Theory \& Practice, 13(2), 739-745.

Ferraioli, S. J., \& Harris, S. L. (2011). Effective educational inclusion of students on the autism spectrum. Journal of Contemporary Psychotherapy, 41(1), 19-28.

Gresham, F. M. (2016). Social Skills Assessment and Intervention for Children and Youth. Cambridge Journal of Education, 46(3), 319-332.

Kasari, C., Chang, Y. C., \& Patterson, S. (2013). Pretending to play or playing to pretend: the case of autism. American Journal of Play, 6(1), 124. 
Laushey, K. M., Heflin, L. J., Shippen, M., Alberto, P. A., \& Fredrick, L. (2009). Concept mastery routines to teach social skills to elementary children with high functioning autism. Journal of Autism and Developmental Disorders, 39(10), 1435-1448.

Leekam, S. R., Prior, M. R., \& Uljarevic, M. (2011). Restricted and repetitive behaviors in autism spectrum disorders: a review of research in the last decade. Psychological Bulletin, 137(4), 562.

Lillard, A. S., Lerner, M. D., Hopkins, E. J., Dore, R. A., Smith, E. D., \& Palmquist, C. M. (2013). The impact of pretend play on children's development: a review of the evidence. Psychological Bulletin, 139(1).

Neely, M. N., Walter, E., Black, J. M., \& Reiss, A. L. (2012). Neural correlates of humor detection and appreciation in children. The Journal of Neuroscience, 32(5), 1784-1790.

Rabi, N. M., Teck, W. K., Abdullah, N., Nasir, N. A. W. M., \& Nordin, N. S. (2020). Social Communication Skills' Criteria for Placement of Student with Disabilities in Inclusive Program. International Journal of Academic Research in Business and Social Sciences, 10(3), 645-655.

Radici, E., Heboyan, V., Mantovani, F., \& De Leo, G. (2019). Teachers' Attitudes Towards Children Who Use AAC in Italian Primary Schools. International Journal of Disability, Development and Education, 66:3, 284-297.

Scattone, D. (2008). Enhancing the conversation skills of a boy with asperger's disorder through social stories and video modeling. Journal of Autism and Developmental Disorders, 38(2), 395-400.

Simion, E. (2014). Augmentative and alternative communication - support for people with severe speech disorders. Procedia - Social and Behavioral Sciences, $12877-81$.

Travers, J. C., Higgins, K., Pierce, T., Boone, R., Miller, S., \& Tandy, R. (2011). Emergent literacy skills of preschool students with autism: A comparison of teacher-led and computerassisted instruction. Education and Training in Autism and Developmental Disabilities, 46(3), 326-338. 